\title{
Tauopathy models and human neuropathology: similarities and differences
}

\author{
Stephan Frank · Florence Clavaguera $\cdot$ Markus Tolnay
}

Received: 2 July 2007 / Revised: 21 August 2007 / Accepted: 22 August 2007 / Published online: 5 September 2007

(C) Springer-Verlag 2007

\begin{abstract}
Much of our current understanding of the pathogenic mechanisms in human neurodegenerative disorders has been derived from animal studies. As such, transgenic mouse models have significantly contributed to the development of novel pathogenic concepts underlying human tauopathies, a group of diseases comprising various forms of neurodegenerative disorders including Alzheimer's disease, corticobasal degeneration, argyrophilic grain disease, progressive supranuclear palsy, and Pick's disease as well as hereditary fronto-temporal dementia with parkinsonism linked to chromosome 17. Here, we will review in vivo models of human tauopathies with particular preference to transgenic mouse models. Strengths and limitations of these models in recapitulating the complex pathogenesis of tauopathies will be discussed.
\end{abstract}

Keywords Neurodegeneration - Tau - Amyloid-cascade . GSK3 $\cdot$ Phosphorylation $\cdot$ Microtubule

\section{Introduction}

Pathologic alterations in the microtubule-associated protein tau have been linked to the pathogenesis of a number of neurodegenerative disorders, including Alzheimer's disease (AD), progressive supranuclear palsy (PSP), corticobasal degeneration (CBD), argyrophilic grain disease (AgD), Pick's disease (PD), as well as a subset of hereditary frontotemporal dementias (FTDs), which are therefore also

S. Frank · F. Clavaguera $\cdot$ M. Tolnay $(\varangle)$ Institute of Pathology, Department of Neuropathology, University Hospital Basel, Schönbeinstrasse 40,

4031 Basel, Switzerland

e-mail: mtolnay@uhbs.ch collectively classified as tauopathies [24, 49, 87]. In these diseases, the microtubule-associated protein tau accumulates, forming detergent-resistant intracellular inclusions known as neurofibrillary tangles (NFTs). In AD, the temporal and spatial distribution of tau pathology correlates well with the clinical disease severity [9]. However, whether it acts as the primary culprit or is indirectly involved in the pathogenic pathways culminating in neuronal cell loss, is still hotly contested. Although pathogenic tau mutations have been identified in FTD with parkinsonism linked to chromosome 17 (FTDP-17T) which is clear evidence of tau dysfunction playing a pivotal role in neurodegeneration, the mechanism of tau dysfunction leading to neuronal demise is only poorly understood.

In many ways, human tauopathies represent a heterogeneous group of diseases, with affected patients presenting with diverse clinico-pathological phenotypes ranging from prototypical aphasia to dementia syndromes. It is therefore of utmost importance to elucidate the mechanisms of tau accumulation and NFT formation in these diseases, and in particular to answer the question of whether all tauopathies develop through a unifying common pathogenic pathway. On the molecular level, the phenotypic diversity of tauopathies is attributable to different types of tau gene mutations as well as additional modifying genetic and epigenetic factors. Whereas on the cellular level, not only neuronal but also glial cell elements can be affected by tau-related pathology in locoregionally different and disease- (and sometimes also stage-) specific patterns, heterogeneity on the biochemical level is reflected by the expression of different tau isoforms. These isoforms arise through alternative splicing, yielding variants with differential binding to microtubules according to the presence of either three (3R isoforms) or four microtubule-binding repeat domains (4R isoforms). Homologous repeat sequences are also present in 
the microtubule-associated proteins MAP2 and MAP4. As a major microtubule-associated protein, mammalian tau is subject to extensive regulation on the transcriptional level and to post-translational modification, in particular to phosphorylation, resulting in complex biochemical patterns [51]. Through binding to microtubules, tau is involved in the initiation and stabilization of these structures, which, in neurons, are critical for axonal transport and proper synaptic function [84]. Of particular note, overexpression of tau in neuronal cell lines as well as in primary neurons leads to disturbed kinesin-dependent trafficking of organelles along microtubule tracts $[21,86]$. In particular, mitochondria fail to be transported to peripheral cell compartments, which may represent an important pathogenic mechanism for neurodegeneration [79], contributing to the loss of synapses as an early event in AD pathogenesis [14, 83].

In the adult human brain, six tau isoforms are expressed that are generated through alternative splicing [12, 23, 49]. These isoforms differ by containing either three or four microtubule-binding domains within their C-termini (3R and $4 \mathrm{R}$ isoforms, respectively) with additional variability arising from the existence of none, one or two N-terminal inserts $(0 \mathrm{~N}, 1 \mathrm{~N}, 2 \mathrm{~N}$ isoforms). The $4 \mathrm{R}$ isoforms bind to microtubules more avidly than the $3 \mathrm{R}$ variants. Isoform expression patterns are developmentally regulated with the $3 \mathrm{R}$ variants being expressed during early life phases ("fetal tau") and it has therefore been hypothesized that expression of $3 \mathrm{R}$ tau might be associated with the higher degree of plasticity that is required during neuronal development [26]. Although in embryonic hippocampal slice cultures of tau-null mice an inhibition of neuronal maturation can be demonstrated [19], tau-deficient mice appear physiologically normal, are able to reproduce and do not develop obvious neurological phenotypes, presumably because other microtubule-associated proteins (such as MAP1A and 1B) can compensate for tau loss [31].

For quite some time, interest in tau as an important pathogenic factor in AD-related neurodegeneration has lagged behind the research efforts devoted to the amyloid beta peptide $(\mathrm{A} \beta)$, partly because tau pathology was commonly accepted to occur downstream of $\mathrm{A} \beta$ according to the beta amyloid cascade hypothesis [32]. However, in various other tauopathies, prominent tau pathology develops in the absence of extracellular $\mathrm{A} \beta$ deposits. In addition, the identification of tau mutations underlying the pathogenesis of FTDP-17T [39, 68, 75], a neurodegenerative FTD entity which follows an autosomal-dominant mode of inheritance, has sparked intense research efforts aimed at the generation of animal models not only to decipher the role of tau in neurodegeneration but also at deriving novel therapeutic approaches for human tauopathies.

Remarkably, several crucial features of human tauopathies have been recapitulated in relatively simple organisms, such as Caenorhabditis elegans and Drosophila melanogaster. However, in these models many pathogenic aspects are overly simplified and therefore considerably limit the interpretation of findings in terms of drawing parallels to the pathogenic pathways at play in human tauopathies. Consequently, various tau transgenic ( $\operatorname{tg}$ ) mouse lines have been generated to closer model aspects of the very complex, multi-facet pathogenesis of human tauopathies. After briefly summarizing selected findings in $C$. elegans and $D$. melanogaster, we will focus this review on the various $\mathrm{tg}$ mouse models that have been generated to experimentally recapitulate important histopathological, and sometimes also behavioral features of tauopathies.

\section{Modeling tauopathies in C. elegans}

Caenorhabditis elegans represents an easy to genetically manipulate model for the experimental characterization of normal gene function as well as for exploring pathogenic protein dysfunction. To model tauopathy disorders, several transgenic worm models have been generated [10, 46, 61]. Neuronal expression of normal and FTDP-17T associated mutant human tau proteins (P301L, V337M) [46] caused progressive uncoordinated locomotion, indicative of a nervous system defect, which culminated on day 9 with worms becoming nearly immobile. Moreover, expression of wildtype (wt) human tau was associated with a decreased life span [46]. Interestingly, the transgenic tau protein expressed in $C$. elegans was found to be phosphorylated at analogous residues as it occurs in human tauopathies [46], an observation recently confirmed independently [10]. Of note, whereas no neuronal degeneration was reported by the latter group, transgenic human tau was demonstrated to become highly phosphorylated and to assume a PHF-like conformation [10]. Significantly, FTDP-17T mutant tau lines exhibit a more severe phenotype marked by the production of more detergent-insoluble tau and by a more severe axonal degeneration in comparison to wt-tau expressing lines [46]. In particular, in the line expressing the FTDP-17Tassociated V337M tau mutation, the high level of insoluble tau was paralleled by extensive axonal degeneration [46]. Nerve cell degeneration, accompanied by tau-accumulation in cell bodies and neuronal processes, was recently also reported for another transgenic worm model where the P301L and R406W mutations were expressed in mechanosensory neurons [61]. Thus, the induced tau pathology in worms resembles the situation in human tauopathies in so far as there is progressive accumulation of hyperphosphorylated insoluble tau as well as neurodegeneration with one of the main differences being the absence of overt tau tangle formation in C. elegans. Nevertheless, 
in summary, these experiments provided evidence for at least a contributory (if not primary causal) role of tau in neurodegenerative processes and thus points to a high degree of evolutionary conservation in tau-associated pathogenesis.

\section{Lessons from Drosophila}

Bridging the simplicity of $C$. elegans and the complexity of vertebrate models, D. melanogaster has become an invaluable tool for the study of neurodegenerative diseases [6]. At least $50 \%$ of Drosophila genes have human homologs and more than $70 \%$ of human disease genes have Drosophila homologs, making the (rather primitive) fly a relevant organism to model selected aspects of human diseases, including neurodegenerative disorders. Drosophila flies possess one single tau gene, which is expressed in many types of neurons, where in analogy to mammalian neuronal cells, tau protein can also accumulate within axonal processes [33]. Wittmann et al. [95] have generated transgenic D. melanogaster flies as a genetic model of tau-associated neurodegenerative disorders by expressing wt and mutant (R406W, V337M) forms of human tau which recapitulated key features of human tauopathies. Despite only moderate levels of transgene expression, transgenic flies exhibited adult onset progressive neurodegeneration with a significantly reduced life span, especially in the R406W tg fly lines. With relative anatomic selectivity abnormal tau protein accumulated, but NFT formation was not observed. In summary, these results indicated that tau-induced neurodegeneration in flies does occur in the absence of large tau filamentous aggregates [95]. Moreover, overexpression of the human tau homolog in Drosophila neurons induces apoptosis, which is not accompanied by the formation of intracellular NFTs [6, 22, 43]. This finding, which, prima vista, would argue against a significant cytotoxic role of tau-rich NFTs, could reflect a mode of neurotoxicity which depends on protein alterations occurring prior to the assembly of fibrillar aggregates such as on smaller proteolytic tau fragments, which-at least in the human system - were recently postulated to be pathogenically important by promoting aggregation through nucleation effects $[50,67,93]$. However, when wt human tau (4R isoform) was coexpressed with the fly homolog of glycogen synthase kinase-3beta (one of the known tauphosphorylating kinases) in another Drosophila model, NFTs were observed [43]. Thus, Drosophila tau models may faithfully replicate several important aspects of human tauopathies, including tau hyperphosphorylation, accumulation, and fibril formation as well as neuronal degeneration.

\section{Mouse models}

A considerable number of mouse tauopathy models have been generated that not only recapitulated key histopathological hallmarks of tauopathies but, to a variable degree, also reproduced important behavioral aspects of the respective human disorders. Tauopathies are morphologically heterogeneous disorders, with neuronal and/or glial cell components affected in rather disease-specific and sometimes stereotypic spatiotemporal patterns [24, 49, 87]. On the molecular level, it should be noted, that in contrast to the adult human brain only $4 \mathrm{R}$ variants of the murine tau homolog are endogenously expressed in the adult mouse brain. Furthermore, major AD-related phosphorylation sites of human tau are conserved in the murine protein, including those phosphorylated by the major tau kinases glycogen synthase-kinase $3 \beta$ (GSK-3 $\beta$ ) and cyclin-dependent kinase 5 (CDK5), both of which also serve crucial roles during neurodevelopment $[16,17,44]$. Of note, with regard to $\mathrm{AD}$ pathogenesis, $\beta$-amyloid has been shown to trigger tau phosphorylation by activating GSK-3 $\beta$ and CDK5 $[44,48]$. It therefore seems that the mouse lends itself as a model organism to recapitulate essential aspects of tauopathies. However, as will be discussed below, extreme care needs to be exercised in the interpretation of histopathological findings and the results of behavioral tests. Depending on the promoter system chosen to drive transgene expression, the phenotypes of tg mouse models often differ strikingly even if the very same transgene is expressed. Whereas, the murine thy- 1 promoter favors transgene expression especially in brain stem and spinal cord (which consequently often results in an axonopathy-related pathology through the preferential affection of the long fiber tracts), others such as the $\alpha$-calcium-calmodulin-dependent kinase-II (CaMK-II) promoter target expression predominantly to the forebrain giving rise to behavioral phenotypes. In addition, gene dosage effects and altered ratios of expressed tau isoforms (i.e., $4 \mathrm{R}$ versus $3 \mathrm{R}$ variants) have to be taken into account. Furthermore, through the use of additional promoters, cell-type specific transgene expression (neuronal versus glial expression) can be achieved. Moreover, different promoters yield variable transgene expression levels, which is extremely relevant as pathological protein aggregation including the assembly of fibrillar protein deposits is concentration-dependent. Last but not least, as will be discussed in more detail below, phenotypes of tg mice show striking variance depending on whether transgene expression occurs in the murine endogenous or in a knockout background. Thus, currently existing tg mouse models can only recapitulate selected aspects of human tauopathies. With regard to the multiple molecular pathways that have so far been implicated with the rather complex pathogenesis of these diseases, it currently seems more than questionable 
whether the generation of mouse models which faithfully mirror the full human disease phenotypes will ever be achieved. Rather, a more realistic view seems that by carefully putting together the single pieces of information that are provided by each of the mouse models, a picture will emerge in the hopefully not too distant future that permits understanding the complex pathogenic pathways in tauopathies well enough to devise rationale, effective and possibly individualized therapeutic approaches to combat these devastating diseases.

\section{Models with tg expression of human wt tau isoforms (Table 1)}

\section{Modeling neuronal pathology}

The initial mouse models for human tauopathies allowed only specific human tau isoforms to be studied within the background of endogenous wt murine tau. The first tg mouse models were generated more than a decade ago, when pathogenic tau mutations had not yet been identified, by expressing the longest human brain tau isoform $(4 \mathrm{R} / 2 \mathrm{~N})$ under the control of the human thy-1 promoter [29]. The tg human tau protein was found to be expressed in neuronal cell bodies, axons and dendrites. Interestingly, the tg tau protein, expressed at rather low levels, was phosphorylated at the same sites that are hyperphosphorylated in the paired helical filaments in human AD brains. In the absence of NFTs this observed pathology [29] was therefore interpreted as a pre-tangle phenotype, to be considered as intracellular "precursor" lesion preceding the full-blown tau NFT pathology associated with tauopathies $[3,8]$. In a similar mouse model where the human $4 \mathrm{R} / 2 \mathrm{~N}$ isoform was expressed under the control of the murine thy1 (thy-1.2, respectively) promoter, prominent somatodendritic tau expression and hyperphosphorylation was demonstrated $[69,77]$ (Fig. 1a, b). These mice exhibited severe axonopathy with signs of Wallerian degeneration reflected by axonal breakdown and myelin sheath disintegration. Moreover, severe motor symptoms with neurogenic hindleg muscle atrophy, as histologically verified by the presence of grouped small angular muscle fibers, developed in these animals $[69,77]$.

In further models, alternative promoters such as the one for mouse prion protein (MoPrP) were used to control transgene expression which resulted in even more pronounced phenotypes. Two tg models, in which the shortest human brain isoform of tau $(3 \mathrm{R} / 0 \mathrm{~N})$ was expressed, were created [11, 41]. Brion et al. [11], using a mouse model with rather low $3 \mathrm{R}$ tau transgene expression driven by the murine, house-keeping type HMG-CoA-reductase promoter, did not find NFTs in mice younger than 19 months of age, but the tg protein was demonstrated to be phosphorylated at sites known from tau proteins of paired helical filaments. In contrast, using the MoPrP promoter to drive transgene expression, insoluble, hyperphosphorylated tau progressively accumulated and NFT-like argyrophilic intraneuronal inclusions consisting of tau-immunoreactive filaments were observed in these mice as early as at 6 months of age [41]. Due to high-transgene expression in spinal cord motor neurons, variable axonopathy with formation of tau-immunoreactive spheroids and histomorphological correlates of axonal degeneration was found. Of note, the tau inclusions, although stainable by the Bodian silver method, were not detectable by the Gallyas procedure, which detects most NFTs in human tauopathies [90]. Nevertheless, although formation of bona fide NFTs was not observed (unless the mice reached a very old age [42]), these were the first tg mice to recapitulate key features of human tauopathies. The follow-up analysis of these mice at 12-24 months of age [42] revealed that the fibrillary tau lesions had now converted into AD-like tangle structures detectable by the Gallyas silver impregnation method. The particular relevance of this model was that, for the first time, an age-dependent maturation of tau inclusions culminating in the assembly of insoluble, filamentous, Gallyas-positive NFTs was experimentally recapitulated.

As pointed out earlier, the interpretation of these mouse models, while being valuable first steps to explore the role of tau in neurodegeneration, was restricted by the fact that only one specific isoform of human tau was transgenically expressed. To avoid this caveat, alternative novel mouse models were created. Duff et al. [20] generated mice that overexpressed a human tau transgene containing not only the coding regions but also intronic as well as regulatory sequences. Thus, in these mice, all six human tau isoforms were expressed at the mRNA and protein level in the CNS but when compared to human brain the ratio of $3 \mathrm{R}: 4 \mathrm{R}$ human tau isoforms differed as relatively more $3 R$ tau was present in these mouse brains. However, due to the presence of $4 \mathrm{R}$ endogenous murine tau there was no imbalance of the total 3R:4R ratio. Tau-positive axonal swellings developed in the spinal cords of the mice and correlated with a hind-limb abnormality, but no other neuropathological abnormalities, in particular no tangle formation, were seen [20]. In an even more sophisticated approach, Andorfer et al. [2] generated a tg mouse model that produces all six human tau isoforms in the absence of endogenous mouse (4R) tau, shifting the isoform ratio toward the $3 R$ variants. Notably, these mice developed tau filaments by the age of 9 months, and pathological tau accumulated in cell bodies and neuronal dendrites in a spatiotemporal-relevant pattern. Resembling AD pathology, tau aggregation predominantly occurred in the neocortical neurons and pyramidal hippocampal cells, whereas brain stem and spinal cord were almost devoid of tau lesions. There was no 


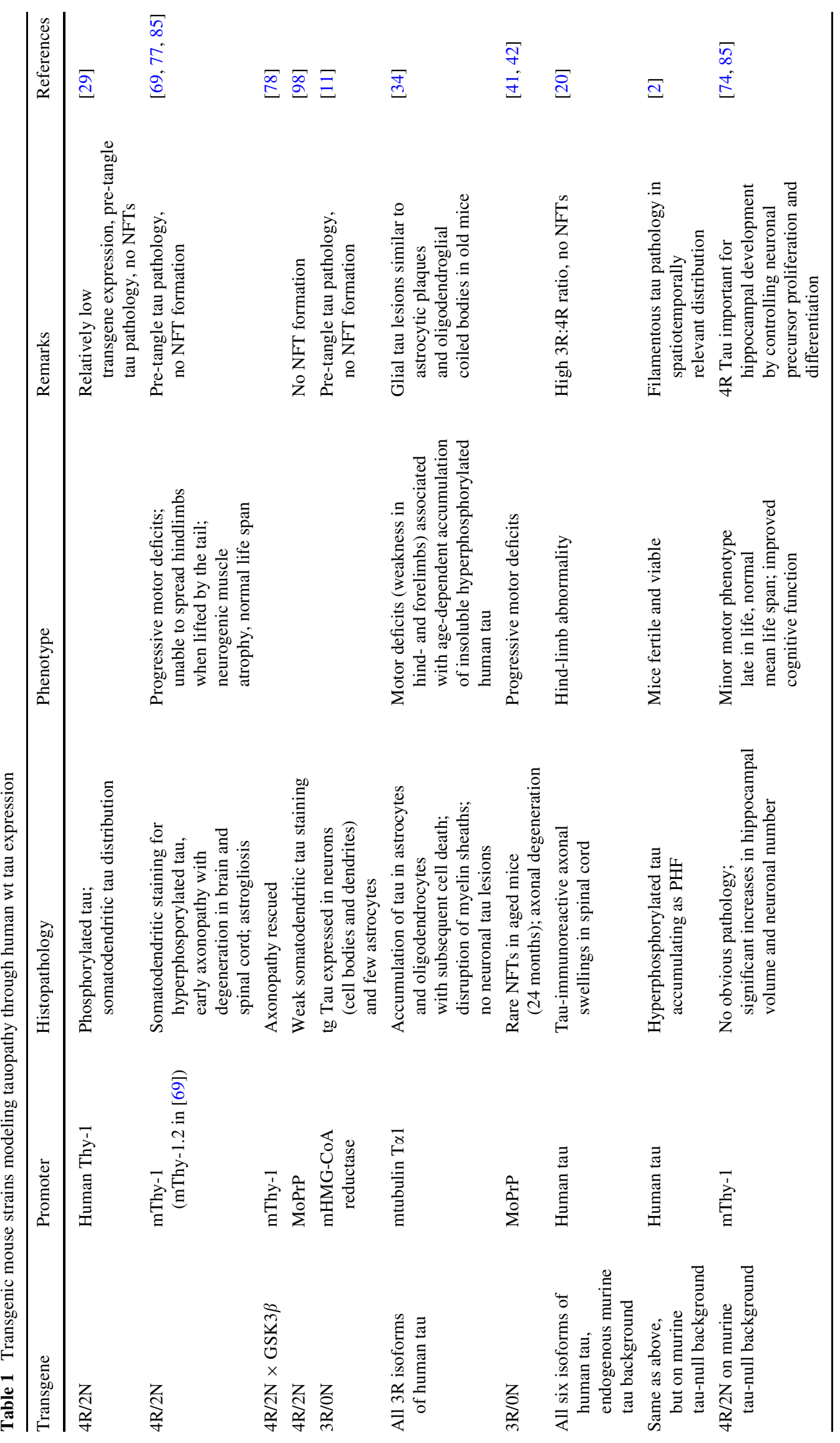


Fig. 1 a Abundant tau stained (phosphorylation-dependent anti-tau antibody AT8) pre-tangle neurons are observed in sector CA1 of a transgenic mouse strain expressing the longest human four-repeat tau isoform [64]. b Notably this pre-tangle pathology is not stained by the Gallyas silver technique. c AT8 stained neurofibrillary tangles (NFT) in the brainstem region of a transgenic mouse strain expressing the human P301S mutation [1]. $\mathbf{d}$ In contrast to the pre-tangle pathology obtained in mouse strains expressing human wild-type tau isoforms NFT in P301S mice are strongly stained with Gallyas. Scale bar a-d: $100 \mu \mathrm{m}$

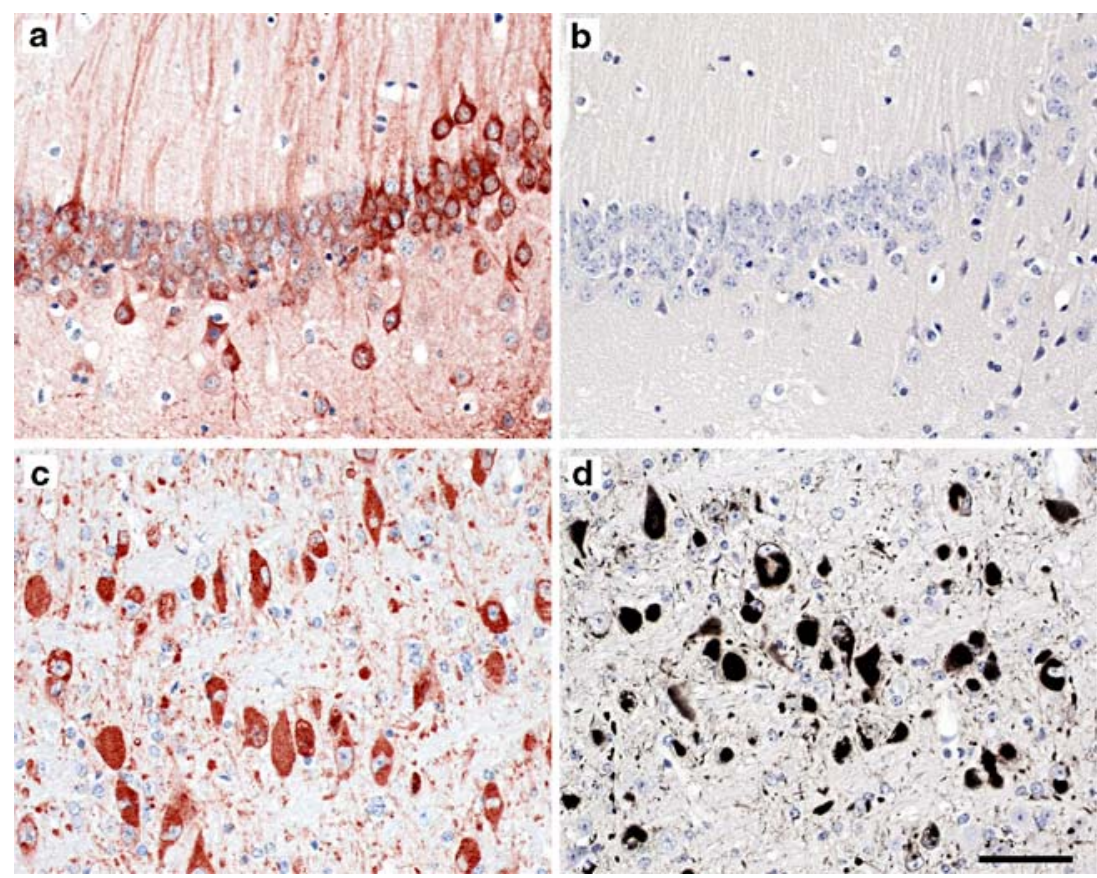

evidence of significant motor or behavioral abnormalities. Subsequently, Van Leuven and co-workers [85] established a mouse model where the human tau- $4 \mathrm{R} / 2 \mathrm{~N}$ isoform was expressed in a tau-null background backcrossed into FVB/ $\mathrm{N}$. These mice survive normally and display only a minor motor phenotype, which occurs late in life in the absence of tau aggregates [85]. Of note, also in contrast to $4 \mathrm{R} / 2 \mathrm{~N}$ tg mouse models with the endogenous mouse tau background $[69,77]$ no obvious pathology, in particular no axonopathy was observed [85]. Instead, in a very similar model of mice expressing the $4 \mathrm{R} / 2 \mathrm{~N}$ isoform in a murine tau-k.o. C57/ BL6 background analysis revealed significant increases in hippocampal volume and neuron numbers with improved hippocampal memory retention [74]. It was concluded from this study that $4 \mathrm{R}$-tau serves an important function during hippocampal development by controlling neuronal precursor proliferation and differentiation [74]. Interpreting the results of these tg models, the ensuing question of whether endogenous murine tau is inhibitory to tau filament formation, remains to be answered unambiguously. The large excess of wt human tau in most of these models suffices to induce mild "pre-tangle" pathology, marked by an abnormal non-filamentous accumulation of phosphorylated tau in cell bodies and dendrites with an associated axonopathy and variable motor symptoms. However, even with the use of strong promoters, high-level expression of wt tau iswith two exceptions $[2,42]$ —not sufficient to cause the formation of bona fide NFTs as well as significant neuronal losses. Remarkably, especially in light of the amyloid cascade hypothesis, this also holds true for mice that coexpress amyloid precursor protein (APP) harboring the Swedish and London mutations $\left(\mathrm{APP}_{751 \mathrm{SL}}\right)$ and the presenilin-1 M146L mutant ( $\mathrm{PS} 1_{\mathrm{M} 146 \mathrm{~L}}$ ) combined with the human 3R/ $0 \mathrm{~N}$ wt tau transgene under control of a modified HMG-CoA reductase promoter [7]. Only when the human $3 \mathrm{R}$ isoform is expressed under control of the MoPrP promoter, few Gallyas-positive NFT-like structures are observed in mice aged 24 months [42]. Moreover, the Andorfer et al. study [2] recapitulated for the first time tau hyperphosphorylation with formation of fibrillary tau aggregates by transgenically expressing all six human tau isoforms in a murine tau-k.o. background.

\section{Modeling glial pathology}

While the tg mouse models discussed above strongly focused on studying tau in CNS neurons, the filamentous glial tau pathology characteristic of CBD, PSP, AgD, and most FTDP-17T cases had been neglected so far. Götz et al. [30] and Higuchi et al. [34] were the first to report on tg mice that modeled tau-associated neurodegeneration of glial cells. When all three isoforms of human 3Rtau were expressed under the control of the mouse T $\alpha 1 \alpha$-tubulin promoter, filamentous, Gallyas-positive aggregates reminiscent of astrocytic plaques were observed whichalthough not specific - are considered rather typical lesions in CBD [13]. These lesions developed in older mice and no formation of tau aggregates was detected in neurons [34]. Furthermore, recapitulating typical findings in PSP, CBD, and $\mathrm{AgD}$, Gallyas-positive, tau-immunoreactive oligodendroglial coiled body-like structures were found which correlated with an age-dependent accumulation of filamentous 
tau in degenerating oligodendroglial cells [34]. Thus, the formation of tau-positive glial lesions as they occur in certain human tauopathies can be modeled in transgenic mice. As will be discussed in the following section, FTDP-17Tassociated tau mutants were also expressed using alternative glia-targeting promoters to model human glial tau pathology $[30,36]$.

\section{Models with tg expression of human mutant tau isoforms (Table 2)}

\section{Modeling neuronal pathology}

Soon after the identification in 1998 of pathogenic tau mutations in a subset of FTDP-17 families (reviewed in [92]), various groups were successful in creating tg mouse models in which NFT formation was recapitulated in vivo. Both, neuronal $[1,27,53,80,82]$ and glial tau filamentous pathologies $[30,36]$ were demonstrated. Tau gene mutations that underlie the pathogenesis of certain hereditary tauopathies such as FTDP-17T either occur near splice sites, changing ratios within the expressed tau isoform repertoire, or occur as missense mutations, both of which likely affect the binding affinity of tau toward microtubules. In the first reported mouse model which successfully demonstrated the formation of NFTs, the human P301L mutation, which results in pronounced adverse effects on microtubule-assembly promoting activity [4], was expressed under the control of the MoPrP promoter [53] leading in homozygous mice to mutant human tau expression at a twofold level in comparison to endogenous murine levels. In homozygous mice, motor and behavioral deficits related to NFT formation started to develop at 4.5 months with NFTs and Pick body-like neuronal lesions occurring in amygdala, mid-brain, brain stem and spinal cord, and with pre-tangle tau pathology in the neocortex, hippocampus, and basal ganglia. In addition to a significant reduction of spinal cord motor neurons that almost reached 50\%, a peripheral neuropathy accompanied by neurogenic muscle atrophy was observed. Biochemically, the presence of Gallyas-positive NFTs containing hyperphosphorylated tau was demonstrated. One of the significant advances achieved through this model was that, for the first time, a link between neurofibrillary pathology and neuronal loss was established. Remarkably, a relatively low transgene expression level was sufficient to trigger fibrillary tau aggregates. In contrast, previous mouse models with higher expression levels of the human wt tau transgene failed to cause NFT formation, which likely reflects the pathogenicity of P301L as the most common tau gene mutation associated with FTDP-17T (reviewed in [92]).

Expressing the same P301L transgene, however under the control of the murine thy-1.2 promoter, Götz et al. [27] similarly observed hyperphosphorylation of accumulated tau which appeared redistributed from its normal axonal localization to somatodendritic compartments. In addition, as demonstrated by electron microscopy, short filament formation occurred in the cortex, brain stem and spinal cord [27]. Likewise, using a very similar model controlled by the murine thy-1 promoter, $w$ t human $4 \mathrm{R} / 2 \mathrm{~N}$ tau was expressed in one mouse strain comparatively to the P301L mutation [85]. Whereas in the wt tau mice motor symptoms were evident already at 6-8 weeks, no tau aggregates formed and the animals had a normal life span. In contrast, in the P301L transgene-expressing mice, progressive fibrillary tau aggregation started to develop at around 6 months of age and, despite only minor motor problems, animals died prior to the age of 13 months [85]. Tangle-like tau pathology was also observed in mice that expressed the P301L mutation in combination with a tet-off regulated CaMK-II promoter system [70, 72]. As expected, high-level P301L expressing mice developed pre-tangles as early as at 2.5 months of age, with rapid progression of tau pathology culminating both in NFT formation by around 4 months of age and marked cognitive impairment. NFTs were first observed in the neocortex and, with increasing age, progressed to the hippocampus and the limbic system [70, 72]. Remarkably, when transgenic P301L expression was suppressed by administration of doxycycline, memory function was significantly improved, but NFTs continued to accumulate, and a region-specific dissociation between neuronal loss and the occurrence of NFTs was verified [76]. This may also be related to a postulated dissociation between the mechanisms causing memory impairment and those leading to tau fibrillation. It seems that in this model NFTs per se are not the primary cause of the observed cognitive deficits [72] which may rather be reflections of a reversible neuronal dysfunction.

Interestingly, proteomic analyses of P301L tg mice revealed a mitochondrial dysfunction related to modification in the expression patterns of mitochondrial respiratory chain complex components, antioxidant enzymes implicated in detoxification of reactive oxygen species (ROS) and of synapse-associated proteins [18]. In the context of tauopathies, mitochondrial dysfunction has also independently been corroborated in vivo by several groups. For instance, chronic rotenone-mediated complex I inhibition is sufficient to trigger a cerebral tauopathy with tau accumulations occurring in neurons, astrocytes, and oligodendrocytes [38].

In mice expressing the human P301S tau mutant associated with early onset FTDP-17T, two groups demonstrated neurodegeneration leading to nerve cell loss. In these models starting at 5-6 months, filamentous hyperphosphorylated tau pathology develops in brain stem and spinal cord with a significant reduction of spinal cord motor neurons in 


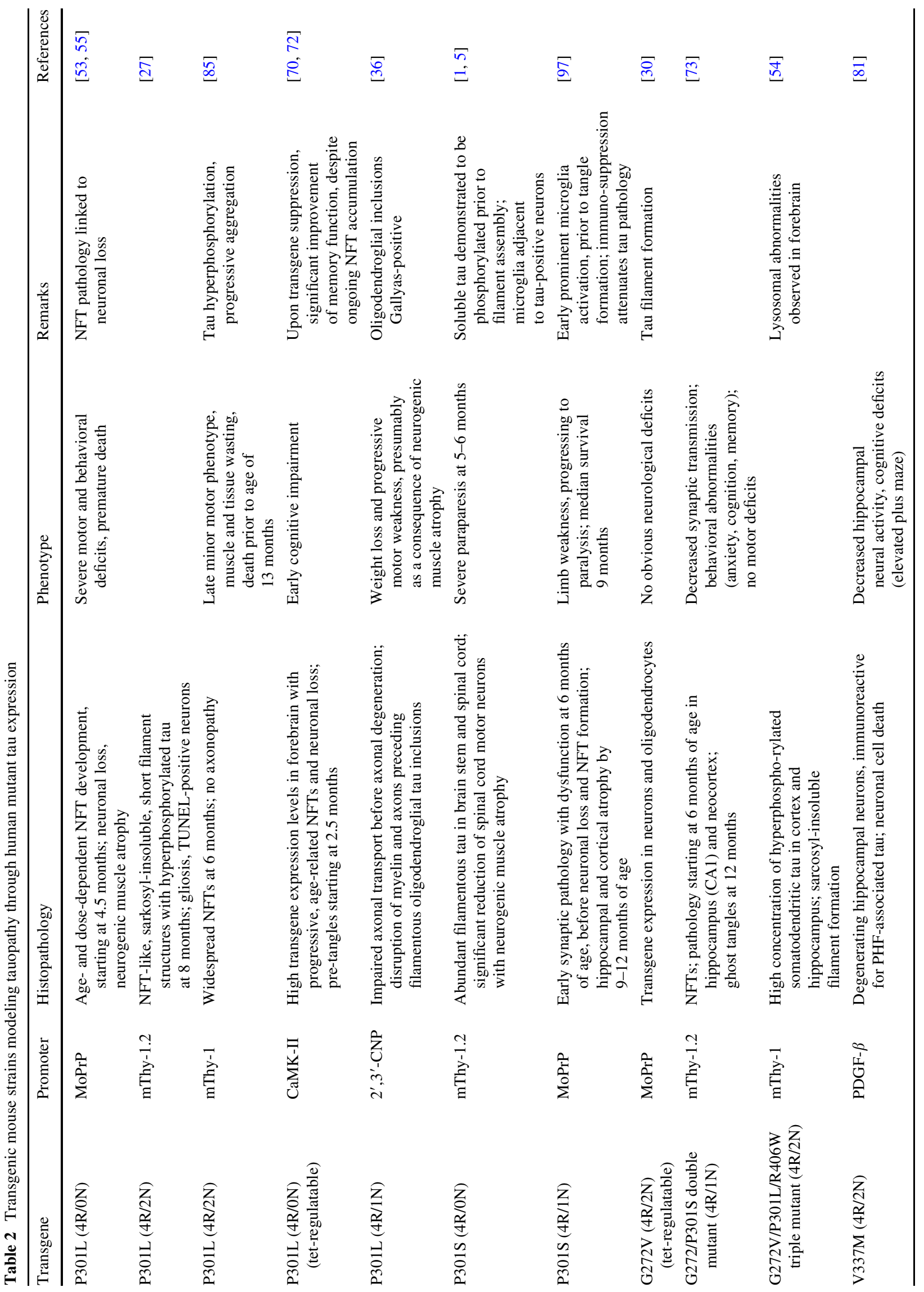




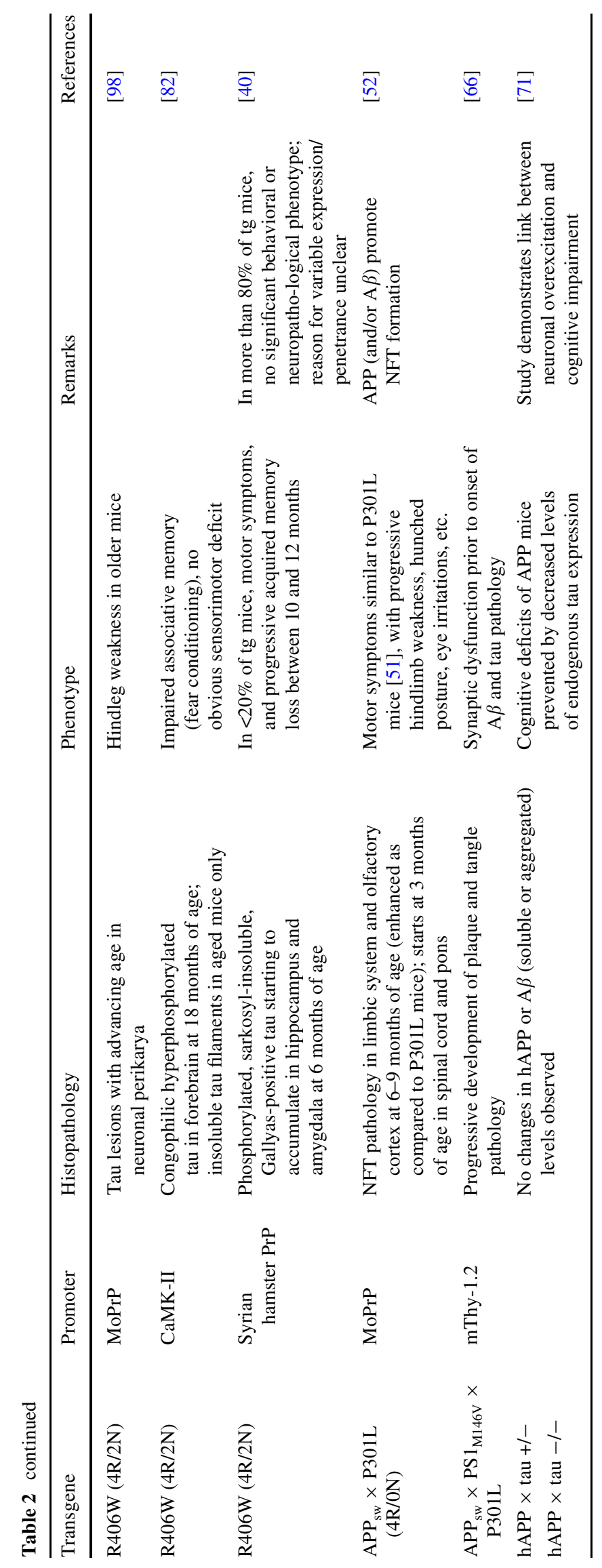


homozygous mice in conjunction with severe paraparesis [1, 5, 97] (Fig. 1c, d). Remarkably, Bellucci et al. [5] also reported on microglia activation-recently implicated in the clearance of $\mathrm{A} \beta$ deposits (for review see [96])—adjacent to tau-positive neurons.

In an alternative model of FTDP-17T, the human V337M mutation that is weaker in comparison to the P301L mutation with regard to affecting microtubuleassembly was expressed under the control of the PDGF- $\beta$ promoter. This resulted in the formation of tau-containing NFTs in the hippocampus and in various behavioral abnormalities [81]. Similarly, when the FTDP-17T-associated R406W mutation was expressed using the CaMK-II promoter, congophilic hyperphosphorylated tau inclusions formed in the forebrain starting at 18 months of age, with aged mice exhibiting an impaired associative memory but no significant sensorimotor deficits. Sarcosyl-insoluble tau was recovered from old tg mice only [82]. Expression of the same mutant, but under control of the Syrian hamster prion protein promoter, led to the development of filamentous tau aggregations in the hippocampus and amygdala with subsequent spreading of tau pathology to neocortical and subcortical regions. Accumulated, sarcosyl-insoluble tau was found to be phosphorylated, ubiquitinated, and stainable with the Gallyas silver impregnation method [40]. Again, in analogy to the P301S mouse model reported by Bellucci et al. [5], a pronounced activation of microglia was prominent. Behavioral tests of the R406W tg mice revealed motor symptoms as well as progressive loss of acquired memory at the age of 10-12 months [40]. In a third tg human tau R406W mouse strain, with expression driven by the MoPrP promoter, Zhang et al. [98] similarly observed filamentous tau lesions with advancing age, which occurred in neuronal perikarya of the cerebral cortex, hippocampus, cerebellum, and spinal cord. Interestingly, when compared to otherwise identical tg mice expressing human wt tau, reduced tau levels were found in CNS axons and linked to retarded axonal transport, presumably resulting from an accumulation of insoluble R406W but not human wt tau protein [98]. In yet another model, where G272V and P301S mutations were coexpressed in a thy-1.2-regulated manner, hyperphosphorylation and Gallyas-positive NFTlike pathology were observed. These mice developed defective hippocampal synaptic transmission as well as behavioral and cognitive abnormalities such as increased anxiety, learning deficits, and impaired spatial memory [73]. Finally, Lim et al. [54] reported on a tg mouse model expressing human triple mutant tau under control of the murine thy- 1 promoter. All of these mutants $(\mathrm{G} 272 \mathrm{~V}$, P301L, and R406W) have been found in FTDP-17T kindreds [39]. Transgenic expression of this triple mutant at relatively low levels led to fibrillar, hyperphosphorylated tau pathology in neurons, in particular of cortical and hippocampal regions. Transgene expression was low in the spinal cord, and no obvious motor deficits were observed up to 12 months [54].

In summary, in mouse lines engineered to express FTDP-17T-associated missense mutations, abundant filaments containing hyperphosphorylated tau protein developed, which was associated with neuronal cell loss. The fact that phosphorylation was observed in soluble tau points to the fact that hyperphosphorylation is likely to occur prior to filament assembly. Indeed, as demonstrated [63], an increase in tau phosphorylation in the soluble tau fraction may result in increased filament formation, indicating that phosphorylation of tau plays a contributory, if not causal role in the process of tau self-aggregation [63]. However, one crucial question that has not been answered yet in vivo is whether tau phosphorylation represents a primary event or occurs secondarily to the tau protein undergoing subtle conformational (pathological) changes.

\section{Modeling glial pathology}

Finally, two tg models where FTDP-17T mutations were expressed to model glial tau pathology, shall be briefly mentioned here. In the first approach, Götz et al. [30] expressed the human G272V mutation with a MoPrP promoter-autoregulatory tetracycline-dependent transactivator system and found transgene expression in neurons as well as oligodendrocytes. Although formation of filamentous tau associated with phosphorylation of the protein was observed, these mice did not develop any obvious neurological deficits [30]. In yet another P301L tg mouse strain with transgene expression regulated by an oligodendrocytespecific promoter $\left[2^{\prime}, 3^{\prime}\right.$-cyclic nucleotide $3^{\prime}$-phosphodiesterase (CNP)], Higuchi et al. [36] demonstrated the mutant tau in CNS oligodendrocytes to become insoluble and filamentous at 15 months of age. In these mice, disruption of myelin and axonal degeneration occurred, and subsequent motor deficits developed. Finally, coiled body-like NFT formation in oligodendrocytes was also revealed in $\mathrm{tg}$ P301L mice (MoPrP promoter) described earlier [53, 55].

\section{Double and triple transgenic mice as models for $\mathrm{AD}$ pathogenesis (Table 2)}

Alzheimer's disease is neuropathologically characterized by two signature lesions, extracellular plaque-like deposition of $\mathrm{A} \beta$ as well as intracellular formation of NFTs containing hyperphosphorylated tau. Despite several decades of research efforts, it is still not known whether or not both pathologies are causally related to each other. According to the amyloid cascade hypothesis [32], and possibly in the reality of $\mathrm{AD}$, they are in that $\mathrm{A} \beta$ is likely to function upstream to trigger tau pathology. Along these lines, $\mathrm{A} \beta$ 
oligomers have recently been shown to impair proteasome activity, thereby enhancing tau accumulation [89]. Moreover, APP mutations are causally linked to early onset forms of $\mathrm{AD}$, but no tau mutations have ever been linked to the disease. However, at least outside the context of AD, the general validity of the hypothesis can be questioned by a number of observations. First, in PSP, CBD, AgD, and FTDP-17T, neurodegeneration occurs in the absence of $\mathrm{A} \beta$ pathology. Second, it is interesting to note that tg mutant APP mice, despite showing extensive parenchymal and vascular amyloid pathology, do not develop robust tauopathyrelated changes (see review by van Leuven [91]). Furthermore, it was recently reported that intraneuronal $\mathrm{A} \beta$ immunoreactivity may not be predictive of neurofibrillary tau pathology [94]. On the other hand, double tg mice, coexpressing mutant APP and the P301L tau mutation develop not only $\mathrm{A} \beta$ as well as tau pathology, but also display amyotrophy and severe motor problems [52]. In addition, triple tg mice (3xTg-AD) overexpressing mutant APP (harboring the Swedish mutation), the M146V presenilin-1 mutant, and the P301L mutant tau, exhibit a combined, progressive tau and amyloid pathology [66]. Synaptic dysfunction with deficits in long-term potentiation manifested prior to the occurrence of plaques and tangles [66]. Interestingly, in this model amyloid deposition precedes NFT formation, consistent with the amyloid cascade hypothesis [65]. Moreover, when proteasome function is blocked in $3 \times \mathrm{Tg}-\mathrm{AD}$ mice at a prepathological stage, a marked increase in tau as well as $\mathrm{A} \beta$ accumulation ensues [89]. Furthermore, by intracerebrally injecting $\mathrm{A} \beta 42$ fibrils into P301L mice an increase in NFTs was triggered in the amygdala from where neuronal projections run to the injection sites, which is clearly indicative of a pathogenic link between $\mathrm{A} \beta$ and tau [28].

In another recent approach it was tested whether lowering the expression of endogenous tau could block $\mathrm{A} \beta$ induced cognitive impairments. To this end, human APP transgenic mice [60] were crossed with tau knockout animals. Remarkably, ablation of endogenous murine tau prevents the $\mathrm{A} \beta$-dependent behavioral deficits that typically develop in human tg APP mice, without having any measurable effects on amyloid plaque load [71]. Another important aspect of that same work [71] is that tau may have a role in regulating nerve cell activity and that lowering levels of tau expression might represent a strategy to inhibit hyperexcitability-induced damage of CNS neurons; the underlying molecular correlates of this excitotoxic tau effect remain to be clarified.

\section{Therapeutic approaches}

So far, available therapeutic approaches have only met with limited success, with only a few approved modalities that- only transiently-slow cognitive decline [58]. Perhaps, unless the primary cause(s) triggering the neuronal cell death cascade in tauopathies are targeted, there are only modest chances to succeed in developing highly efficient therapeutic strategies capable of preventing or at least halting the vicious circle of neurodegeneration in these disorders.

According to the amyloid cascade hypothesis, reduction of the culprit $\mathrm{A} \beta$, supposed to act upstream of tau, appears to be an obvious strategy. However, recent reports (e.g. [71]) indicate that reducing tau may be an equally warranted, effective, and possibly complementing approach.

A number of additional strategies are conceivable, one of them targeting abnormal tau phosphorylation. The longest adult tau variants contain almost 80 potential serine and threonine phosphorylation sites, although only about 30 of them seem to be functionally relevant under physiological conditions [12]. The phosphorylation status of tau can be modulated by the prolyl-isomerase Pin1 [56] which catalyzes the conversion between two distinct phospho(Ser/ Thr)-Pro motif conformations, thereby perhaps also indirectly promoting tau dephosphorylation. Interestingly, Pin 1 knockout mice exhibit progressive, age-dependent motor and behavioral deficits, accompanied by tau hyperphosphorylation, tau filament formation, and neuronal degeneration [56]. Apart from Pin1, in particular three kinases, GSK-3 [57], CDK5 [63], and ERK2 [47] have been associated with modulating tau phosphorylation in vivo. Of note, $\operatorname{tg}$ mice overexpressing GSK-3 display tau hyperphosphorylation, disrupted microtubules, and apoptotic neurons [57]. Interestingly, conditional expression of dominantnegative GSK-3 (unexpectedly, the constitutive GSK-3 knockout is embryonically lethal due to massive apoptosis in the liver [37]), leads to increased neuronal apoptosis and motor symptoms, both of which are suppressed when transgene expression is switched off [25]. In another experimental approach, the administration of an orally bioavailable, blood-brain barrier-penetrating small molecule inhibitor of ERK2 to tg P301L mice was effective not only at significantly reducing hyperphosphorylated tau but also in preventing the typical motor deficits in these animals. Remarkably, however, there was no concomitant reduction of NFTs, suggesting that tau cytotoxicity is not so much exerted by NFTs but may rather be caused by smaller tau aggregates. The prevention of hyperphosphorylation through inhibition of one of the tau-phosphorylating kinases may also point to a crucial pathogenic role of dysregulated tau phosphorylation in tauopathies [47].

However, CDK5, ERK2, and GSK-3 also function to regulate various important physiological pathways, necessitating the design of kinase inhibitors that effectively suppress tau hyperphosphorylation while showing only minimal toxicity through off-target effects. If successful, such kinase 
inhibitors (recently reviewed in [59]) might yield a valuable adjunct to currently available treatment options.

In addition, administration of lithium-chloride, a drug traditionally used in the treatment of bipolar disorders, has recently been shown not only to inhibit GSK-3 activity but also to result in decreased tau pathology [62], which strongly correlated with markedly reduced axonal degeneration in P301L tg mice [64]. Other alternative (although currently more theoretic) approaches could be aimed at preventing the proteolytic cleavage-mediated generation of small, nucleation-promoting tau fragments through inhibition of specific proteases such as calpain or caspases [15, 35]. Stabilizing microtubules might represent another potential therapeutic avenue (for review see [87]). Agents with respective activity, in particular taxols such as paclitaxel are commonly used in cancer treatment (recently reviewed in [45]). As they act on dividing cells, adverse effects are hard to be avoided. Nevertheless, treatment of $\mathrm{tg}$ mice expressing the $3 \mathrm{R} / 0 \mathrm{~N}$ isoform of human wt tau with paclitaxel resulted not only in the restoration of fast axonal transport but also led to the improvement of motor deficits [99]. Finally, as $\mathrm{A} \beta$ oligomers were recently demonstrated to enhance tau accumulation through impaired proteasome activity, the proteasome appears to be another attractive target for therapeutic intervention [89].

\section{Open questions}

Admittedly, despite decades of intense research, many of the central questions underlying the pathogenic mechanisms in tauopathies still remain unanswered. In particular, the nature of the triggering event(s) initiating tau aggregation in vivo remains enigmatic. One of the questions that arises in that context is whether tau phosphorylation is a general prerequisite for filament formation and if so, how both processes are linked. To what extent are the nucleation-promoting effects mediated by smaller, proteolytically derived tau fragments important events in filamentous aggregation? If the amyloid cascade hypothesis is correct, what are the mechanisms of $\mathrm{A} \beta$ triggering tau filament assembly? Which species of tau are the toxic ones? Do filamentous tau aggregates even act in a protective way by promoting the sequestration of the toxic species? Finally, what is the role of inflammation related to the development of tau pathology? What is the basis for the $\mathrm{AD}$-stage-specific spatio-temporal distribution of tau lesions?

\section{Conclusions}

Despite the fact that the available animal models cannot sufficiently mirror the complex pathogenesis of human tau- opathies, they will continue to provide important new insights into the molecular pathways at play in these disorders. In particular, genetically engineered mouse models will continue to lead the way in tauopathy research. Rather than completely reflecting the entire pathogenic process with all its different aspects, they can be used to adequately recapitulate crucial aspects of these disorders. One of their particular strengths is that, even under the highly artificial conditions of transgene overexpression, our comprehension/understanding of tauopathies can be further expanded by studies of protein interactions as well as of induced protein modifications and their consequences. Last but not least, using worms and flies may pay off as well, e.g., in high-throughput drug-screens which may lead to the identification of agents that lend themselves for the designing of novel therapeutic strategies for these devastating diseases.

Acknowledgments $\mathrm{FC}$ and $\mathrm{MC}$ are supported by the Swiss National Science Foundation (3100-068328).

\section{References}

1. Allen B, Ingram E, Takao M, Smith MJ, Jakes R, Virdee K, Yoshida H, Holzer M, Craxton M, Emson PC, Atzori C, Migheli A, Crowther RA, Ghetti B, Spillantini MG, Goedert M (2002) Abundant tau filaments and nonapoptotic neurodegeneration in transgenic mice expressing human P301S tau protein. J Neurosci 22:9340-9351

2. Andorfer C, Kress Y, Espinoza M, de Silva R, Tucker KL, Barde YA, Duff K, Davies P (2003) Hyperphosphorylation and aggregation of tau in mice expressing normal human tau isoforms. J Neurochem 86:582-590

3. Bancher C, Brunner C, Lassmann H, Budka H, Jellinger K, Wiche G, Seitelberger F, Grundke-Iqbal I, Iqbal K, Wisniewski H (1989) Accumulation of abnormally phosphorylated tau precedes the formation of neurofibrillary tangles in Alzheimer's disease. Brain Res 477:90-99

4. Barghorn S, Zheng-Fischhöfer Q, Ackmann M, Biernat J, von Bergen M, Mandelkow EM, Mandelkow E (2000) Structure, microtubule interactions, and paired helical filament aggregation by tau mutants of frontotemporal dementias. Biochemistry 39:1171411721

5. Bellucci A, Westwood AJ, Ingram E, Casamenti F, Goedert M, Spillantini MG (2004) Induction of inflammatory mediators and microglial activation in mice transgenic for mutant human P301S tau protein. Am J Pathol 165:1643-1652

6. Bonini NM, Fortini ME (2003) Human neurodegenerative disease modeling using Drosophila. Annu Rev Neurosci 26:627-656

7. Boutajangout A, Authelet M, Blanchard V, Touchet N, Tremp G, Pradier L, Brion JP (2004) Characterisation of cytoskeletal abnormalities in mice transgenic for wild-type human tau and familial Alzheimer's disease mutants of APP and presenilin-1. Neurobiol Dis 15:47-60

8. Braak E, Braak H, Mandelkow EM (1994) A sequence of cytoskeleton changes related to the formation of neurofibrillary tangles and neuropil threads. Acta Neuropathol (Berl) 87:554-567

9. Braak H, Braak E (1991) Neuropathological stageing of Alzheimer-related changes. Acta Neuropathol (Berl) 82:239-259

10. Brandt R, Gergou A, Wacker I, Fath T, Hutter H (2007) A Caenorhabditis elegans model of tau hyperphosphorylation: induction of 
developmental defects by transgenic overexpression of Alzheimer's disease-like modified tau. Neurobiol Aging. June 21 [Epub ahead of print]

11. Brion JP, Tremp G, Octave JN (1999) Transgenic expression of the shortest human tau affects its compartmentalization and its phosphorylation as in the pretangle stage of Alzheimer's disease. Am J Pathol 154:255-270

12. Buée L, Bussière T, Buée-Scherrer V, Delacourte A, Hof PR (2000) Tau protein isoforms, phosphorylation and role in neurodegenerative disorders. Brain Res Brain Res Rev 33:95-130

13. Cairns NJ, Bigio EH, Mackenzie IR, Neumann M, Lee VM, Hatanpaa KJ, White CL, Schneider JA, Grinberg LT, Halliday G, Duyckaerts C, Lowe JS, Holm IE, Tolnay M, Okamoto K, Yokoo H, Murayama S, Woulfe J, Munoz DG, Dickson DW, Ince PG, Trojanowski JQ, Mann DM (2007) Neuropathologic diagnostic and nosologic criteria for frontotemporal lobar degeneration: consensus of the Consortium for Frontotemporal Lobar Degeneration. Acta Neuropathol (Berl) 114:5-22

14. Coleman PD, Yao PJ (2003) Synaptic slaughter in Alzheimer's disease. Neurobiol Aging 24:1023-1027

15. Cotman CW, Poon WW, Rissman RA, Blurton-Jones M (2005) The role of caspase cleavage of tau in Alzheimer disease neuropathology. J Neuropathol Exp Neurol 64:104-112

16. Cruz JC, Tsai LH (2004a) A Jekyll and Hyde kinase: roles for Cdk5 in brain development and disease. Curr Opin Neurobiol 14:390-394

17. Cruz JC, Tsai LH (2004b) Cdk5 deregulation in the pathogenesis of Alzheimer's disease. Trends Mol Med 10:452-458

18. David DC, Hauptmann S, Scherping I, Schuessel K, Keil U, Rizzu P, Ravid R, Dröse S, Brandt U, Müller WE, Eckert A, Götz J (2005) Proteomic and functional analyses reveal a mitochondrial dysfunction in P301L tau transgenic mice. J Biol Chem 280:23802-23814

19. Dawson HN, Ferreira A, Eyster MV, Ghoshal N, Binder LI, Vitek MP (2001) Inhibition of neuronal maturation in primary hippocampal neurons from tau deficient mice. J Cell Sci 114:1179-1187

20. Duff K, Knight H, Refolo LM, Sanders S, Yu X, Picciano M, Malester B, Hutton M, Adamson J, Goedert M, Burki K, Davies P (2000) Characterization of pathology in transgenic mice overexpressing human genomic and cDNA tau transgenes. Neurobiol Dis 7:87-98

21. Ebneth A, Godemann R, Stamer K, Illenberger S, Trinczek B, Mandelkow E (1998) Overexpression of tau protein inhibits kinesin-dependent trafficking of vesicles, mitochondria, and endoplasmic reticulum: implications for Alzheimer's disease. J Cell Biol 143:777-794

22. Fortini ME, Bonini NM (2000) Modeling human neurodegenerative diseases in Drosophila: on a wing and a prayer. Trends Genet 16:161-167

23. Goedert M (1996) Tau protein and the neurofibrillary pathology of Alzheimer's disease. Ann NY Acad Sci 777:121-131

24. Goedert M, Spillantini MG (2006) A century of Alzheimer's disease. Science 314:777-781

25. Gomez-Sintes R, Hernandez F, Bortolozzi A, Artigas F, Avila J, Zaratin P, Gotteland JP, Lucas JJ (2007) Neuronal apoptosis and reversible motor deficit in dominant-negative GSK-3 conditional transgenic mice. EMBO J 26:2743-2754

26. Goode BL, Feinstein SC (1994) Identification of a novel microtubule binding and assembly domain in the developmentally regulated inter-repeat region of tau. J Cell Biol 124:769-782

27. Götz J, Chen F, Barmettler R, Nitsch RM (2001a) Tau filament formation in transgenic mice expressing P301L tau. J Biol Chem 276:529-534

28. Götz J, Chen F, van Dorpe J, Nitsch RM (2001b) Formation of neurofibrillary tangles in P3011 tau transgenic mice induced by Abeta 42 fibrils. Science 293:1491-1495
29. Götz J, Probst A, Spillantini MG, Schafer T, Jakes R, Burki K, Goedert M (1995) Somatodendritic localization and hyperphosphorylation of tau protein in transgenic mice expressing the longest human brain tau isoform. Embo J 14:1304-1313

30. Götz J, Tolnay M, Barmettler R, Chen F, Probst A, Nitsch RM (2001c) Oligodendroglial tau filament formation in transgenic mice expressing G272V tau. Eur J Neurosci 13:2131-2140

31. Harada A, Oguchi K, Okabe S, Kuno J, Terada S, Ohshima T, Sato-Yoshitake R, Takei Y, Noda T, Hirokawa N (1994) Altered microtubule organization in small-calibre axons of mice lacking tau protein. Nature 369:488-491

32. Hardy J (2006) Has the amyloid cascade hypothesis for Alzheimer's disease been proved? Curr Alzheimer Res 3:71-73

33. Heidary G, Fortini ME (2001) Identification and characterization of the Drosophila tau homolog. Mech Dev 108:171-178

34. Higuchi M, Ishihara T, Zhang B, Hong M, Andreadis A, Trojanowski J, Lee VM (2002) Transgenic mouse model of tauopathies with glial pathology and nervous system degeneration. Neuron 35:433-446

35. Higuchi M, Tomioka M, Takano J, Shirotani K, Iwata N, Masumoto H, Maki M, Itohara S, Saido TC (2005a) Distinct mechanistic roles of calpain and caspase activation in neurodegeneration as revealed in mice overexpressing their specific inhibitors. J Biol Chem 280:15229-15237

36. Higuchi M, Zhang B, Forman MS, Yoshiyama Y, Trojanowski JQ, Lee VM (2005b) Axonal degeneration induced by targeted expression of mutant human tau in oligodendrocytes of transgenic mice that model glial tauopathies. J Neurosci 25:9434-9443

37. Hoeflich KP, Luo J, Rubie EA, Tsao MS, Jin O, Woodgett JR (2000) Requirement for glycogen synthase kinase-3beta in cell survival and NF-kappaB activation. Nature 406:86-90

38. Höglinger GU, Lannuzel A, Khondiker ME, Michel PP, Duyckaerts C, Féger J, Champy P, Prigent A, Medja F, Lombes A, Oertel WH, Ruberg M, Hirsch EC (2005) The mitochondrial complex I inhibitor rotenone triggers a cerebral tauopathy. J Neurochem 95:930-939

39. Hutton M, Lendon CL, Rizzu P, Baker M, Froelich S, Houlden H, Pickering-Brown S, Chakraverty S, Isaacs A, Grover A, Hackett J, Adamson J, Lincoln S, Dickson D, Davies P, Petersen RC, Stevens M, de Graaff E, Wauters E, van Baren J, Hillebrand M, Joosse M, Kwon JM, Nowotny P, Che LK, Norton J, Morris JC, Reed LA, Trojanowski J, Basun H, Lannfelt L, Neystat M, Fahn S, Dark F, Tannenberg T, Dodd PR, Hayward N, Kwok JB, Schofield PR, Andreadis A, Snowden J, Craufurd D, Neary D, Owen F, Oostra BA, Hardy J, Goate A, van Swieten J, Mann D, Lynch T, Heutink $\mathrm{P}$ (1998) Association of missense and $5^{\prime}$-splice-site mutations in tau with the inherited dementia FTDP-17. Nature 393:702-705

40. Ikeda M, Shoji M, Kawarai T, Kawarabayashi T, Matsubara E, Murakami T, Sasaki A, Tomidokoro Y, Ikarashi Y, Kuribara H, Ishiguro K, Hasegawa M, Yen SH, Chishti MA, Harigaya Y, Abe K, Okamoto K, St George-Hyslop P, Westaway D (2005) Accumulation of filamentous tau in the cerebral cortex of human tau R406W transgenic mice. Am J Pathol 166:521-531

41. Ishihara T, Hong M, Zhang B, Nakagawa Y, Lee MK, Trojanowski JQ, Lee VM (1999) Age-dependent emergence and progression of a tauopathy in transgenic mice overexpressing the shortest human tau isoform. Neuron 24:751-762

42. Ishihara T, Zhang B, Higuchi M, Yoshiyama Y, Trojanowski JQ, Lee VM (2001) Age-dependent induction of congophilic neurofibrillary tau inclusions in tau transgenic mice. Am J Pathol 158:555-562

43. Jackson GR, Wiedau-Pazos M, Sang TK, Wagle N, Brown CA, Massachi S, Geschwind DH (2002) Human wild-type tau interacts with wingless pathway components and produces neurofibrillary pathology in Drosophila. Neuron 34:509-519 
44. Kaytor MD, Orr HT (2002) The GSK3 beta signaling cascade and neurodegenerative disease. Curr Opin Neurobiol 12:275-278

45. Kingston DG, Newman DJ (2007) Taxoids: cancer-fighting compounds from nature. Curr Opin Drug Discov Devel 10:130-144

46. Kraemer BC, Zhang B, Leverenz JB, Thomas JH, Trojanowski JQ, Schellenberg GD (2003) Neurodegeneration and defective neurotransmission in a Caenorhabditis elegans model of tauopathy. Proc Natl Acad Sci USA 100:9980-9985

47. Le Corre S, Klafki HW, Plesnila N, Hübinger G, Obermeier A, Sahagún H, Monse B, Seneci P, Lewis J, Eriksen J, Zehr C, Yue M, McGowan E, Dickson DW, Hutton M, Roder HM (2006) An inhibitor of tau hyperphosphorylation prevents severe motor impairments in tau transgenic mice. Proc Natl Acad Sci USA 103:9673-9678

48. Lee MS, Kwon YT, Li M, Peng J, Friedlander RM, Tsai LH (2000) Neurotoxicity induces cleavage of $\mathrm{p} 35$ to $\mathrm{p} 25$ by calpain. Nature 405:360-364

49. Lee VM, Goedert M, Trojanowski JQ (2001) Neurodegenerative tauopathies. Annu Rev Neurosci 24:1121-1159

50. Lee VM, Kenyon TK, Trojanowski JQ (2005) Transgenic animal models of tauopathies. Biochim Biophys Acta 1739:251-259

51. Lee VM, Trojanowski JQ (2001) Transgenic mouse models of tauopathies: prospects for animal models of Pick's disease. Neurology $56:$ :S26-S30

52. Lewis J, Dickson DW, Lin WL, Chisholm L, Corral A, Jones G, Yen SH, Sahara N, Skipper L, Yager D, Eckman C, Hardy J, Hutton M, McGowan E (2001) Enhanced neurofibrillary degeneration in transgenic mice expressing mutant tau and APP. Science 293:1487-1491

53. Lewis J, McGowan E, Rockwood J, Melrose H, Nacharaju P, Van Slegtenhorst M, Gwinn-Hardy K, Paul Murphy M, Baker M, Yu X, Duff K, Hardy J, Corral A, Lin WL, Yen SH, Dickson DW, Davies P, Hutton M (2000) Neurofibrillary tangles, amyotrophy and progressive motor disturbance in mice expressing mutant (P301L) tau protein. Nat Genet 25:402-405

54. Lim F, Hernández F, Lucas JJ, Gómez-Ramos P, Móran MA, Avila J (2001) FTDP-17 mutations in tau transgenic mice provoke lysosomal abnormalities and Tau filaments in forebrain. Mol Cell Neurosci 18:702-714

55. Lin WL, Lewis J, Yen SH, Hutton M, Dickson DW (2003) Filamentous tau in oligodendrocytes and astrocytes of transgenic mice expressing the human tau isoform with the P301L mutation. Am J Pathol 162:213-218

56. Liou YC, Sun A, Ryo A, Zhou XZ, Yu ZX, Huang HK, Uchida T, Bronson R, Bing G, Li X, Hunter T, Lu KP (2003) Role of the prol$\mathrm{yl}$ isomerase Pin1 in protecting against age-dependent neurodegeneration. Nature 424:556-561

57. Lucas JJ, Hernández F, Gómez-Ramos P, Móran MA, Hen R, Avila J (2001) Decreased nuclear beta-catenin, tau hyperphosphorylation and neurodegeneration in GSK-3beta conditional transgenic mice. Embo J 20:27-39

58. Marx J (2007) Alzheimer's disease. A new take on tau. Science 316:1416-1417

59. Mazanetz MP, Fischer PM (2007) Untangling tau hyperphosphorylation in drug design for neurodegenerative diseases. Nat Rev Drug Discov 6:464-479

60. Mucke L, Masliah E, Yu GQ, Mallory M, Rockenstein EM, Tatsuno G, Hu K, Kholodenko D, Johnson-Wood K, McConlogue L (2000) High-level neuronal expression of abeta 1-42 in wild-type human amyloid protein precursor transgenic mice: synaptotoxicity without plaque formation. J Neurosci 20:4050-4058

61. Miyasaka T, Ding Z, Gengyo-Ando K, Oue M, Yamaguchi H, Mitani S, Ihara Y (2005) Progressive neurodegeneration in C. elegans model of tauopathy. Neurobiol Dis 20:372-383

62. Nakashima H, Ishihara $T$, Suguimoto P, Yokota O, Oshima E, Kugo A, Terada S, Hamamura T, Trojanowski JQ, Lee VM,
Kuroda S (2005) Chronic lithium treatment decreases tau lesions by promoting ubiquitination in a mouse model of tauopathies. Acta Neuropathol (Berl) 110:547-556

63. Noble W, Olm V, Takata K, Casey E, Mary O, Meyerson J, Gaynor K, LaFrancois J, Wang L, Kondo T, Davies P, Burns M, Veeranna, Nixon R, Dickson D, Matsuoka Y, Ahlijanian M, Lau LF, Duff K (2003) Cdk5 is a key factor in tau aggregation and tangle formation in vivo. Neuron 38:555-565

64. Noble W, Planel E, Zehr C, Olm V, Meyerson J, Suleman F, Gaynor K, Wang L, LaFrancois J, Feinstein B, Burns M, Krishnamurthy P, Wen Y, Bhat R, Lewis J, Dickson D, Duff K (2005) Inhibition of glycogen synthase kinase-3 by lithium correlates with reduced tauopathy and degeneration in vivo. Proc Natl Acad Sci USA 102:6990-6995

65. Oddo S, Caccamo A, Kitazawa M, Tseng BP, LaFerla FM (2003a) Amyloid deposition precedes tangle formation in a triple transgenic model of Alzheimer's disease. Neurobiol Aging 24:10631070

66. Oddo S, Caccamo A, Shepherd JD, Murphy MP, Golde TE, Kayed R, Metherate R, Mattson MP, Akbari Y, LaFerla FM (2003b) Triple-transgenic model of Alzheimer's disease with plaques and tangles: intracellular Abeta and synaptic dysfunction. Neuron 39:409-421

67. Park SY, Ferreira A (2005) The generation of a $17 \mathrm{kDa}$ neurotoxic fragment: an alternative mechanism by which tau mediates betaamyloid-induced neurodegeneration. J Neurosci 25:5365-5375

68. Poorkaj P, Bird TD, Wijsman E, Nemens E, Garruto RM, Anderson L, Andreadis A, Wiederholt WC, Raskind M, Schellenberg GD (1998) Tau is a candidate gene for chromosome 17 frontotemporal dementia. Ann Neurol 43:815-825

69. Probst A, Götz J, Wiederhold KH, Tolnay M, Mistl C, Jaton AL, Hong M, Ishihara T, Lee VM, Trojanowski JQ, Jakes R, Crowther RA, Spillantini MG, Burki K, Goedert M (2000) Axonopathy and amyotrophy in mice transgenic for human four-repeat tau protein. Acta Neuropathol (Berl) 99:469-481

70. Ramsden M, Kotilinek L, Forster C, Paulson J, McGowan E, SantaCruz K, Guimaraes A, Yue M, Lewis J, Carlson G, Hutton M, Ashe KH (2005) Age-dependent neurofibrillary tangle formation, neuron loss, and memory impairment in a mouse model of human tauopathy (P301L). J Neurosci 25:10637-10647

71. Roberson ED, Scearce-Levie K, Palop JJ, Yan F, Cheng IH, Wu T, Gerstein H, Yu GQ, Mucke L (2007) Reducing endogenous tau ameliorates amyloid beta-induced deficits in an Alzheimer's disease mouse model. Science 316:750-754

72. Santacruz K, Lewis J, Spires T, Paulson J, Kotilinek L, Ingelsson M, Guimaraes A, DeTure M, Ramsden M, McGowan E, Forster C, Yue M, Orne J, Janus C, Mariash A, Kuskowski M, Hyman B, Hutton M, Ashe KH (2005) Tau suppression in a neurodegenerative mouse model improves memory function. Science 309:476481

73. Schindowski K, Bretteville A, Leroy K, Begard S, Brion JP, Hamdane M, Buee L (2006) Alzheimer's disease-like tau neuropathology leads to memory deficits and loss of functional synapses in a novel mutated tau transgenic mouse without any motor deficits. Am J Pathol 169:599-616

74. Sennvik K, Boekhoorn K, Lasrado R, Terwel D, Verhaeghe S, Korr H, Schmitz C, Tomiyama T, Mori H, Krugers H, Joels M, Ramakers GJ, Lucassen PJ, Van Leuven F (2007) Tau-4R suppresses proliferation and promotes neuronal differentiation in the hippocampus of tau knockin/knockout mice. Faseb J 21:2149-2161

75. Spillantini MG, Murrell JR, Goedert M, Farlow MR, Klug A, Ghetti B (1998) Mutation in the tau gene in familial multiple system tauopathy with presenile dementia. Proc Natl Acad Sci USA 95:7737-7741

76. Spires TL, Orne JD, SantaCruz K, Pitstick R, Carlson GA, Ashe KH, Hyman BT (2006) Region-specific dissociation of neuronal 
loss and neurofibrillary pathology in a mouse model of tauopathy. Am J Pathol 168:1598-1607

77. Spittaels K, Van den Haute C, Van Dorpe J, Bruynseels K, Vandezande K, Laenen I, Geerts H, Mercken M, Sciot R, Van Lommel A, Loos R, Van Leuven F (1999) Prominent axonopathy in the brain and spinal cord of transgenic mice overexpressing four-repeat human tau protein. Am J Pathol 155:2153-2165

78. Spittaels K, Van den Haute C, Van Dorpe J, Geerts H, Mercken M, Bruynseels K, Lasrado R, Vandezande K, Laenen I, Boon T, Van Lint J, Vandenheede J, Moechars D, Loos R, Van Leuven F (2000) Glycogen synthase kinase-3beta phosphorylates protein tau and rescues the axonopathy in the central nervous system of human four-repeat tau transgenic mice. J Biol Chem 275:41340-41349

79. Stamer K, Vogel R, Thies E, Mandelkow E, Mandelkow EM (2002) Tau blocks traffic of organelles, neurofilaments, and APP vesicles in neurons and enhances oxidative stress. J Cell Biol 156:1051-1063

80. Tanemura K, Akagi T, Murayama M, Kikuchi N, Murayama O, Hashikawa T, Yoshiike Y, Park JM, Matsuda K, Nakao S, Sun X, Sato S, Yamaguchi H, Takashima A (2001) Formation of filamentous tau aggregations in transgenic mice expressing V337M human tau. Neurobiol Dis 8:1036-1045

81. Tanemura K, Murayama M, Akagi T, Hashikawa T, Tominaga T, Ichikawa M, Yamaguchi H, Takashima A (2002) Neurodegeneration with tau accumulation in a transgenic mouse expressing V337M human tau. J Neurosci 22:133-141

82. Tatebayashi Y, Miyasaka T, Chui DH, Akagi T, Mishima K, Iwasaki K, Fujiwara M, Tanemura K, Murayama M, Ishiguro K, Planel E, Sato S, Hashikawa T, Takashima A (2002) Tau filament formation and associative memory deficit in aged mice expressing mutant (R406W) human tau. Proc Natl Acad Sci USA 99:13896-13901

83. Terry RD, Masliah E, Salmon DP, Butters N, DeTeresa R, Hill R, Hansen LA, Katzman R (1991) Physical basis of cognitive alterations in Alzheimer's disease: synapse loss is the major correlate of cognitive impairment. Ann Neurol 30:572-580

84. Terwel D, Dewachter I, Van Leuven F (2002) Axonal transport, tau protein, and neurodegeneration in Alzheimer's disease. Neuromolecular Med 2:151-165

85. Terwel D, Lasrado R, Snauwaert J, Vandeweert E, Van Haesendonck C, Borghgraef P, Van Leuven F (2005) Changed conformation of mutant Tau-P301L underlies the moribund tauopathy, absent in progressive, nonlethal axonopathy of Tau- $4 \mathrm{R} / 2 \mathrm{~N}$ transgenic mice. J Biol Chem 280:3963-3973

86. Thies E, Mandelkow EM (2007) Missorting of tau in neurons causes degeneration of synapses that can be rescued by the kinase MARK2/Par-1. J Neurosci 27:2896-2907
87. Tolnay M, Probst A (2003) The neuropathological spectrum of neurodegenerative tauopathies. IUBMB Life 55:299-305

88. Trojanowski JQ, Smith AB, Huryn D, Lee VM (2005) Microtubule-stabilising drugs for therapy of Alzheimer's disease and other neurodegenerative disorders with axonal transport impairments. Expert Opin Pharmacother 6:683-686

89. Tseng BP, Green KN, Chan JL, Blurton-Jones M, Laferla FM (2007) Abeta inhibits the proteasome and enhances amyloid and tau accumulation. Neurobiol Aging. May 31 [Epub ahead of print]

90. Uchihara T (2007) Silver diagnosis in neuropathology: principles, practice and revised interpretation. Acta Neuropathol (Berl) 113:483-499

91. van Leuven F (2000) Single and multiple transgenic mice as models for Alzheimer's disease. Prog Neurobiol 61:305-312

92. van Swieten J, Spillantini M (2007) Hereditary frontotemporal dementia caused by Tau gene mutations. Brain Pathol 17:63-73

93. Wang YP, Biernat J, Pickhardt M, Mandelkow E, Mandelkow EM (2007) Stepwise proteolysis liberates tau fragments that nucleate the Alzheimer-like aggregation of full-length tau in a neuronal cell model. Proc Natl Acad Sci USA 104:10252-10257

94. Wegiel J, Kuchna I, Nowicki K, Frackowiak J, Mazur-Kolecka B, Imaki H, Wegiel J, Mehta PD, Silverman WP, Reisberg B, Deleon M, Wisniewski T, Pirttilla T, Frey H, Lehtimaki T, Kivimaki T, Visser FE, Kamphorst W, Potempska A, Bolton D, Currie JR, Miller DL (2007) Intraneuronal Abeta immunoreactivity is not a predictor of brain amyloidosis-beta or neurofibrillary degeneration. Acta Neuropathol (Berl) 113:389-402

95. Wittmann CW, Wszolek MF, Shulman JM, Salvaterra PM, Lewis J, Hutton M, Feany MB (2001) Tauopathy in Drosophila: neurodegeneration without neurofibrillary tangles. Science 293:711-714

96. Wyss-Coray T (2006) Inflammation in Alzheimer disease: driving force, bystander or beneficial response? Nat Med 12:1005-1015

97. Yoshiyama Y, Higuchi M, Zhang B, Huang SM, Iwata N, Saido TC, Maeda J, Suhara T, Trojanowski JQ, Lee VM (2007) Synapse loss and microglial activation precede tangles in a P301S tauopathy mouse model. Neuron 53:337-351

98. Zhang B, Higuchi M, Yoshiyama Y, Ishihara T, Forman MS, Martinez D, Joyce S, Trojanowski JQ, Lee VM (2004) Retarded axonal transport of R406W mutant tau in transgenic mice with a neurodegenerative tauopathy. J Neurosci 24:4657-4667

99. Zhang B, Maiti A, Shively S, Lakhani F, McDonald-Jones G, Bruce J, Lee EB, Xie SX, Joyce S, Li C, Toleikis PM, Trojanowski JQ, Lee VM (2005) Microtubule-binding drugs offset tau sequestration by stabilizing microtubules and reversing fast axonal transport deficits in a tauopathy model. Proc Natl Acad Sci USA 102:227-231 